Kjor Jensen \& Ole Lauridsen

\title{
Introduction to Thematic Section
}

In this volume of Hermes we present a series of articles on various topics within Romance grammar including grammatology and language history. Hermes 17 published 1996 dealt with English and German grammar including a specifically didactic approach, and thus within a year we have offered an overview of the newest Danish grammar research. 
